\title{
CORRIGENDA
}

\section{Human diploid fibroblasts are resistant to MEK/ERK-mediated disruption of the actin cytoskeleton and invasiveness stimulated by Ras}

Taiko Sukezane, Chitose Oneyama, Kyoko Kakumoto, Kana Shibutani, Hidesaburo Hanafusa and Tsuyoshi Akagi

Oncogene (2005) 24, 8216. doi:10.1038/sj.onc.1209223

Correction to: Oncogene 2005; 24: 5648-5655. doi:10.1038/sj.onc.1208724; published online 20 June 2005

Since publication of the above manuscript, the authors have identified an error on page 5652. In the left-hand column the sentence commencing in the seventh line from the bottom should read 'Therefore, we examined the activation status of MEK and ERK in TIG3/TSR by immunoblotting with antibodies specific for phosphorylated Ser217/221 of MEK and phosphorylated Thr202/tyr204 of ERK.'

The authors also identified errors in Figure 6. The revised version of the Figure is given here.

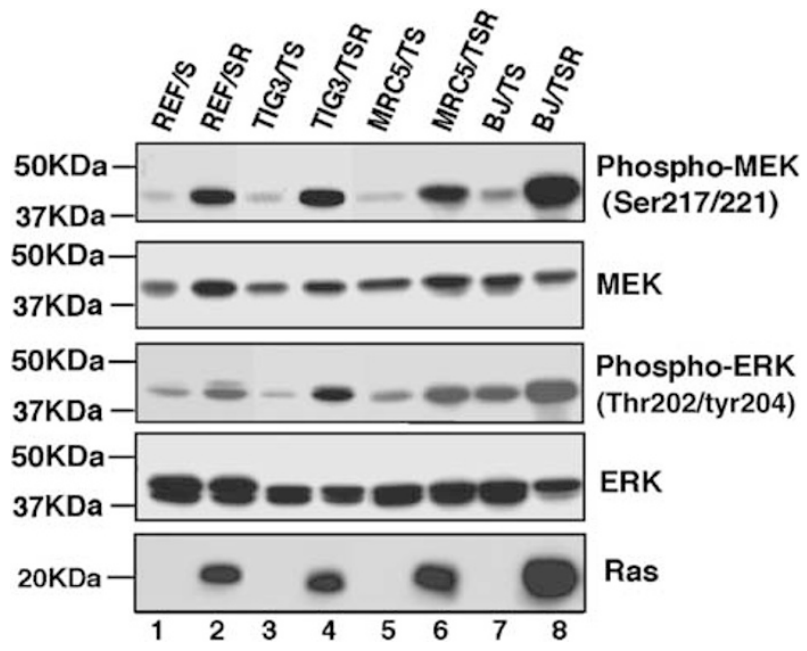

\section{Erythropoietin-mediated activation of JAK-STAT signaling contributes to cellular invasion in head and neck squamous cell carcinoma}

Stephen Y Lai, Erin E Childs, Sichuan Xi, Francesca M Coppelli, William E Gooding, Alan Wells, Robert L Ferris and Jennifer R Grandis

Oncogene (2005) 24, 8216. doi:10.1038/sj.onc.1209224

Correction to: Oncogene 2005; 24: 4442-4449. doi: 10.1038/sj.onc.1208635; published online 18 April 2005

Since publication of the above manuscript, the authors have identified an unintentional omission in the References, and wish to state the following:
Another paper describing the expression and invasion promoting ability of erythropoietin (EPO) and its receptor (EPOR) in head and neck cancer cells was recently published: Mohyeldin A, et al. Erythropoietin signaling promotes invasiveness of human head and neck squamous cell carcinoma. Neoplasia 2005; 7(5):537-543. 